\title{
Compliance amongst asthma patients registered for an asthma disease risk-management programme in South Africa
}

\author{
Authors: \\ Ntombombuso Opedun ${ }^{1}$ \\ Valerie J. Ehlers ${ }^{2}$ \\ Janetta H. Roos ${ }^{2}$ \\ Affiliations: \\ ${ }^{1}$ MA Cur Student, University \\ of South Africa \\ ${ }^{2}$ Department of Health \\ Studies, University of \\ South Africa \\ Correspondence to: \\ Valerie Ehlers \\ Email: \\ ehlervj@unisa.ac.za \\ Postal address: \\ PO Box 65075, Erasmusrand \\ Pretoria 0165 \\ Dates: \\ Received: 29 Oct. 2010 \\ Accepted: 26 July 2011 \\ Published: 27 Sept. 2011 \\ How to cite this article: \\ Opedun, N., Ehlers, V.J. \& \\ Roos, J.H., 2011, 'Compliance \\ amongst asthma patients \\ registered for an asthma \\ disease risk-management \\ programme in South Africa', \\ Curationis 34(1), Art. \#8, \\ 8 pages.doi:10.4102/ \\ Curationis.v34i1.8
}

C 2011. The Authors. Licensee: AOSIS OpenJournals. This work is licensed under the Creative Commons Attribution License.
The study attempted to identify the factors that influence compliance amongst 1039 members and their dependants of a particular medical aid scheme in South Africa who were registered for an asthma disease risk-management (DRM) programme. The sample consisted of 200 systematically selected individuals or their dependants. A quantitative, exploratory, and descriptive study was undertaken. Questionnaires for completion were posted to the individuals or their dependants. The Statistica 7.1 computer program was used to analyse the data.

Most asthma patients did not comply with the DRM programme because they lacked knowledge of the programme. Asthma patients' compliance with the DRM programme can be enhanced by the sustained, positive attitudes of their health providers and case managers; better promotion of the programme; and by involving the patients to a greater extent in the long-term management of their disease.

Asthma patients require education about healthy lifestyles that would empower them to successfully manage their condition, which would prevent or at least reduce asthma attacks and/or hospital admissions.

\section{Introduction}

\section{Problem statement}

The South African medical aid scheme that had been selected to take part in this research project has a disease risk-management (DRM) programme for those who suffer from asthma. However, not all members who have asthma participate in this programme. Effective participation in the DRM programme could help to sustain the effective, long-term treatment of asthma, thereby improving the patient's quality of life, and reduce expenses for the medical aid scheme. The question then arises as to why asthma patients fail to participate in and adhere to the adherence guidelines of the asthma DRM programmes, thereby exposing themselves to potentially lifethreatening asthma attacks.

\section{Background}

According to Smeltzer, Bare, Hinkle and Cheever (2008):

Asthma is a chronic inflammatory disease of the airways that causes airway hyper responsiveness, mucosal edema, and mucus production. This inflammation ultimately leads to recurrent episodes of asthma symptoms: cough, chest tightness, wheezing, and dyspnea ... In 2002, 1.9 million hospital emergency department visits were due to asthma ... and 14 million non-institutionalised adults and 6.4 million children were diagnosed with asthma in the United States of America.

(Smeltzer, Bare, Hinkle \& Cheever 2008:709)

Statistics from the World Health Organization (WHO 2007:1) indicated that 300 million people worldwide suffered from asthma, whilst 255000 had died from asthma during 2005, which emphasises the extent of the global burden of asthma.

Mash, Ainslie, Irusen, Mayers and Bheekie (2007) state that asthma is:

... a common and important chronic disease in South Africa both in terms of its associated morbidity and mortality ... numerous studies have pointed towards deficiencies in terms of clinical management, quality of care and adherence to treatment plans.

(Mash, Ainslie, Irusen, Mayers \& Bheekie 2007:5)

Jeena, Morris and Luyt (2004) have found that asthma tends to run in families and can occur at any age, even in adulthood. Although there is no cure for asthma, it can be controlled. Those 
affected can live normal lives, provided that they adhere to the recommended lifestyle changes and prescribed drugs.

\section{Asthma treatment \\ Asthma is one of the five chronic diseases identified for the DRM programmes of most South African medical aid schemes. Kolbe (2002:564) states that asthma is an expensive illness to treat in terms of preventative treatment and hospitalisations. With effective management, including the avoidance of allergens, prompt treatment of any infection, and adherence to treatment, asthma patients can live relatively normal lives, and can avoid repeated hospitalisations. Hence the implementation of a DRM programme for members who suffer from asthma can help medical aid schemes save money. It can further help to enhance asthmatic patients' quality of life, provided that these patients adhere to their prescriptions and treatment.}

The aim of asthma treatment is to keep lung and airway functions as normal as possible. According to Berkow, Beers, Bogin and Fletcher (1998:175), '... beta-adrenergic receptor agonists are bronchodilators and are the best drugs for relieving sudden attacks of asthma and preventing attacks that may be triggered by exercise'. These drugs stimulate beta-adrenergic receptors to widen the airways. There are two types of bronchodilators: those that act on all betaadrenergic receptors, such as adrenalin; and those, such as albuterol, that act mainly on beta2-adrenergic receptors found on the cells of the lungs. Jeena et al. (2004) discuss two main types of anti-asthma medications, namely preventer and reliever (beta2 agonists) medications. Bronchodilators that act on all beta-adrenergic receptors cause side effects such as tachycardia, restlessness, headaches, and muscle tremors. Bronchodilators that act mainly on beta2-adrenergic receptors cause fewer side effects. Most bronchodilators act within minutes, but the effects last for only four to six hours. Some bronchodilators can be taken orally. Murphy (2005:149) concluded that '.. inhaled corticosteroids are now the preferred treatment for asthma, especially in young children and pregnant women'.

As stated before, the under-treatment of asthma may lead to increased mortality, hospitalisation, morbidity, decreased levels of well-being, and increased costs for the individual and the medical aid scheme.

\section{Non-adherence to asthma treatment regimens}

Elliott (2006:224) maintains that research evidence indicates that adherence to asthma medication is poor amongst adults and children. Non-adherence to these medications causes unscheduled hospital admissions, and is estimated to account for $18 \%-48 \%$ of all deaths directly attributed to asthma. Non-adherence occurs when patients fail to follow the recommendations of their case managers, clinicians, and treatment protocols. The WHO, as cited by Elliott (2006:225), describes non-adherence as a multidimensional phenomenon determined by the interplay of five sets of factors:
- patient-related factors (the fear of side effects and/or addiction)

- condition-related factors (depression)

- therapy-related factors (how the treatment is administered, for instance, inhalers are more challenging to use than swallowing pills)

- health-system related factors (the relationship between the patients and their providers)

- socio-economic factors (the cost of medication and costs to attend appointments).

\section{The basic principles underlying an asthma disease risk-management programme}

An asthma attack, also known as an asthma 'episode' or a 'flare', is any shortness of breath that interrupts the wellbeing of a person who has asthma, and who requires either medication or some intervention to breathe normally again. An asthma attack can occur - amongst other causes - if patients do not take their medication as prescribed, or if they smoke. Asthma attacks often compel the patients to obtain emergency treatment. Medical aid schemes incur very high costs for the admission of patients suffering from asthma to emergency departments and hospitals. The fundamental principle underlying an asthma DRM programme is to reduce the number of asthma attacks and hospitalisations. A case manager, usually a registered nurse, is the coordinator between the patient and the medical aid scheme. Foltz-Gray (1997:50) states that the implementation of an asthma DRM programme requires that patients with a high risk of asthma be identified; that treatment protocols (including drug regimens and laboratory tests) are compiled; that patients are educated about asthma and about their treatment protocols; and that the treatment outcomes must be measured at specific intervals. The most important aspect of an asthma DRM programme is effective and sustained patient education.

\section{Definitions of key concepts}

\section{Asthma}

Brooker (2006:34) defines asthma as a chronic condition of the airways with '... reversible airflow obstruction characterised by dyspnoea, cough and expiratory wheeze due to bronchospasms'. Acute attacks may be caused by exposure to allergens, viral diseases, and non-specific irritating substances.

\section{Compliance}

The Merrian Webster Dictionary (2011) defines the word 'compliance' or 'to comply'as 'the act or process of complying to a desire, demand, proposal, or regimen or to coercion'. According to Elliott (2006:225), compliance implies that a patient's behaviour is congruent with the recommendations of healthcare providers. In this study, 'compliance' means acting according to prescribed treatment regimens: regular exercise, a healthy diet, no smoking, compliance with medication, regular visits to the doctor, regular laboratory tests, keeping follow-up medical appointments, and seeking help timely for signs of chest infections. 


\section{Dependants}

A dependant is a person for whose maintenance another person is responsible. A dependant, according to De Villiers, Van der Merwe and Van Wyk Kotze (2004:21), is a family member or a beneficiary of the principal member of a medical aid scheme. In this study, as set out in the Medical Aid Schemes Act 131 of South Africa (1998:8), the term 'dependant' means any person who, according to the rules of a medical aid scheme, is recognised as a dependant of a principal member, and who is eligible for benefits that are in accordance with the rules of the specific medical aid scheme.

\section{Disease management}

Goldstein (2006:309) states that the term 'disease management' refers to '... a system of coordinated healthcare interventions and communications for populations with conditions in which patient self-care efforts are significant'.

\section{Disease risk-management programme}

This is a wellness programme developed by a specific medical aid scheme that aims to improve the medical care and self-management of patients with chronic illnesses such as diabetes, hypertension, asthma, hyperlipidaemia, and depression by means of patient education. In this study, DRM refers specifically to the DRM programme that a specific medical aid scheme offers to members suffering from asthma, and/or their dependants who suffer from asthma.

\section{Medical aid scheme}

The Medical Aid Schemes Act 131 of South Africa (1998:20) defines a medical aid scheme as a business that is registered by the Registrar of Medical Aid Schemes under certain terms and conditions.

\section{Member}

The New Collins Compact Dictionary of the English Language (2000:313) defines 'members' simply as individuals making up a body or society, or any part of a complex whole. De Villiers et al. (2004:25) consider a member (of a medical aid scheme) as a person who makes contributions to the medical aid scheme based on his or her income and/or the number of his or her dependants. In this study, and in accordance with the Medical Aid Schemes Act 131 of South Africa (1998:8), 'member' means a person who has been admitted as a member of the medical aid scheme in question (South Africa 1998:8).

\section{Prescribed minimum benefits}

By law, prescribed minimum benefits are the specified minimum benefits that medical aid schemes have to provide for life-threatening chronic conditions such as asthma, diabetes, and hypertension. Patients who suffer from asthma and use chronic medication are entitled to a treatment plan that allows them two visits to a pulmonologist per year; two visits to a general practitioner or physician; and tests such as peak-flow evaluations. The treatment plan also allows asthmatics to have one influenza vaccination per year.

\section{Objectives of the study}

The specific objectives for this study were to:

- identify the factors influencing non-compliance amongst the asthma patients registered for the DRM programme of one medical aid scheme

- develop guidelines to improve the compliance of asthma patients with their asthma DRM treatment regimens.

\section{Significance of the study}

The purpose of this study is to contribute toward a more effective DRM asthma programme by enhancing the asthma patients' compliance with their asthma treatment regimens. This could be done by addressing the identified factors that influence these patients' compliance with their asthma treatment protocols.

\section{Research methods and design Design}

A quantitative, exploratory and descriptive design was used to obtain information about the factors influencing asthma patients' non-compliance with their treatment regimens.

\section{Method}

Burns and Grove (2007:40) state that a population comprises all elements (individuals, objects, or substances) that meet the criteria for inclusion in a study. In this survey, the study population comprised 1039 members of a particular medical aid scheme and/or their dependants who had been identified for the asthma DRM programme during 2007. The routine monthly report was used as a sampling frame to obtain membership numbers for the individuals identified for the specific asthma DRM programme.

Systematic sampling was used for this study. Burns and Grove (2007:336) state that the process of systematic sampling involves selecting every $k$ th individual on the list after having randomly selected a starting point. There were 1039 persons registered for the asthma DRM programme. Twenty of the first thirty members were selected for pretesting the questionnaire, and were excluded from the actual data-gathering process. Then 200 members and/or their dependants were selected by choosing every fifth member from the spreadsheet. Of the 200 questionnaires, only 54 (27.0\%) were completed and returned, which then comprised the sample for this study. Despite sending out reminders, no further completed questionnaires were returned. No telephone interviews or follow-up reminders were done as this might have been regarded as compromising individuals' rights to anonymity and confidentiality.

\section{Data-collection methods}

As suggested by Polit and Beck (2004:328), the questionnaire was pre-tested by requesting 20 respondents, who were excluded from participation in the main study, to complete and return the questionnaires to determine the following: 
- the time taken to complete the questionnaire

- whether any items posed difficulties to the respondents' understanding

- whether the respondents regarded any questions as offensive

- whether the sequence of the questions was logical or not.

The feedback obtained during the pre-test phase indicated that the respondents had understood the questions. Hence no changes were made to the questionnaire. The questionnaires were mailed to the members' postal addresses and four weeks later follow-up electronic mails (e-mails) were sent to remind members to complete and return the questionnaires.

\section{Research instrument}

The questionnaire comprised different sections requesting information about the respondents' biographic data, family histories of asthma and other diseases, lifestyle, medical check-ups, laboratory tests done, knowledge of asthma, compliance with their asthma treatment regimens, stress levels, as well as their perceptions about the asthma DRM programme and the case managers of the programme.

\section{Data analysis}

Statistical analysis was used to summarise the results of the study and to reduce, organise and give meaning to the data (Burns \& Grove 2005:43) obtained from the 54 completed questionnaires that were returned. A statistician analysed the data by using the Statistica 7.1 computer program.

\section{Ethical considerations}

To protect the rights of the respondents, permission to conduct the study was obtained from the Management of the participating medical aid scheme, and from the Research and Ethics Committee of the Department of Health Studies at the University of South Africa.

The respondents were informed about the purpose of the study and had a choice as to whether or not to participate in the study. This implies that the response rate of $27.0 \%$ had to be accepted by the researchers. In this study, the respondents' right to fair treatment and the right to privacy were honoured. The identities of the respondents were protected, and the name of the medical aid scheme was kept confidential. Further, all the information obtained from the respondents was kept confidential and treated anonymously. Respondents could complete the questionnaire anonymously. The e-mail addresses were deleted from all the questionnaires returned by e-mail before they were printed out. Only the researchers and the statistician had access to the completed questionnaires that had been locked up in a secure safe. Subsequent to the acceptance of the research report, these completed questionnaires would be destroyed and all traces of them removed from the computer to which the e-mail responses had been sent.

\section{Validity and reliability}

Polit and Beck (2004:416) state that reliability takes into account such characteristics as stability, internal consistency and equivalence. The stability of the instrument can be established by using test-retest reliability. No major discrepancies occurred between responses during the pretest and during the actual data-collection phases. Therefore the test-retest reliability (or stability) of the instrument could be accepted, although no statistical calculations had been done.

Content validity and construct validity were used in this study. According to Polit and Beck (2004:423), '... content validity concerns the degree to which an instrument has an appropriate sample of items for the construct being measured'. Questions about asthma and the asthma DRM programme were asked as this research had been undertaken to verify compliance with the DRM programme amongst members registered for the asthma DRM programme of one medical aid scheme. A literature review was done on asthma and the compliance of patients with asthma-treatment regimens. The items in the questionnaire were based on the literature review. The questionnaire was given to three case managers to determine the relevance of each item regarding clients' compliance with their asthma treatment regimes. The feedback from the case managers was used to change the phrasing of some items on the questionnaire.

According to Burns and Grove (2007:217), construct validity examines the fit between the conceptual definitions and the operational definitions of variables. In this study, the fit between definitions - such as compliance - was examined, as well as possible factors influencing patients' non-compliance with their asthma-treatment regimens.

\section{Discussion of the results Demographic data}

The ages of the 54 respondents ranged from younger than 5 years to older than 61 years of age. As many as $21(38.9 \%)$ of the respondents were 20 years old or younger. More male respondents $(55.6 \% ; n=30)$ than female respondents $(44.4 \% ; n=24)$ participated in the study. Asthma affects both men and women alike. However, some drugs such as Singulair and Flixonase - used in asthma treatment - are contraindicated during pregnancy and breastfeeding as their safety under these conditions has not yet been established. Symbicord is contra-indicated in children under the age of 12 , and during pregnancy and lactation, because its safety under these conditions has also not yet been established (MIMS 2007:228).

\section{Family history of chronic illnesses}

According to McCance and Huether (2006:1222), '... asthma is a familial disorder and over 20 genes have been identified that may play a role in the susceptibility and pathogenesis of asthma'. As many as $68.5 \%(n=37)$ of the respondents indicated that they had a family history of asthma. Family histories of other illnesses included hypertension $(35.2 \%$; $n=19)$ and diabetes $(26.0 \% ; n=14)$. 


\section{Lifestyle}

Lifestyle(for the purpose of this study) includes healthy eating, smoking versus non-smoking, annual flu vaccinations and regular exercise. Smeltzer et al. (2008:225) state that lifestyle provides information about health-related behaviours. These behaviours include patterns of sleep, exercise, nutrition and recreation, as well as personal habits such as smoking and the use of alcohol and caffeine.

\section{Eating habits}

As obesity is a risk factor for asthma, patients who suffer from asthma should follow a healthy eating pattern that will help them maintain a normal body weight. Close to $75 \%$ of emergency-room visits for asthma have been amongst obese individuals. Furthermore, obesity often pre-dates asthma (Medical News Today 2005). Most of the respondents (68.5\%; $n=37$ ) indicated that they followed a healthy eating plan.

\section{Smoking}

Of the respondents, $14.8 \%(n=8)$ were smokers, whilst $27.8 \%(n=15)$ lived with smokers. Ayres (2006:41) indicates that $15 \%-20 \%$ of persons who suffer from asthma, smoke. Smoking can trigger asthma attacks. Children of parents who smoke are prone to more frequent asthma attacks than those of non-smokers.

\section{Exercise}

Of the respondents $37.0 \%(n=20)$ indicated that they did not exercise, whilst $33.3 \%(n=18)$ mentioned that they exercised fewer than three times, $26.0 \%(n=14)$ exercised three to five times a week, and $3.7 \%(n=2)$ exercised six or more times per week. However, the duration of these exercises varied: $33.3 \%(n=18)$ of the respondents exercised for $15-29$ minutes, $20.4 \%(n=11)$ exercised for 30-59 minutes, and 5.5\% $(n=3)$ exercised for 60 minutes or more. To derive benefits from exercising, Mackinnon (2000:S369) maintains that the duration thereof should be at least 30 minutes three times per week and, according to Smeltzer et al. (2008:711), a regular exercise programme can improve lung functions. In the case of children, both Ayres (2006:18) and Promtussananon (2003:75) state that exercise might be erroneously blamed

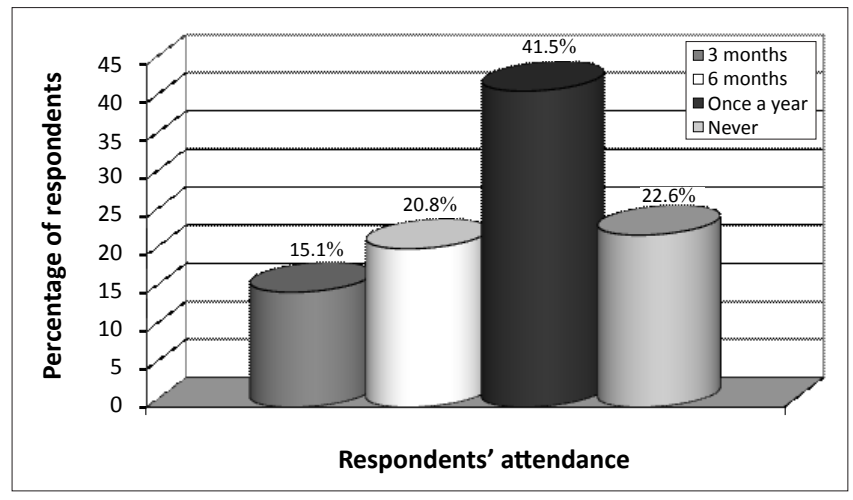

Source: Original data

FIGURE 1: Respondents' annual attendances of medical check-ups per annum $(n=53)$. for precipitating asthmatic symptoms, whilst this should be attributed to general unfitness.

\section{Annual medical check-ups}

Asthma patients should visit their doctors every six months to assess their respiratory functions. Out of the 53 respondents who answered this question, $41.5 \%(n=22)$ had their medical check-ups done once a year, whereas $22.6 \%(n=12)$ did not go for check-ups. Some of these respondents did not go for medical check-ups, yet they had a medical aid care-plan that covered two visits to a doctor annually. Only 20.8\% ( $n=11)$ of the respondents went for their check-ups every six months, and $15.1 \%(n=8)$ went every three months.

\section{Laboratory tests}

Smeltzer and Bare (2004:483-484) maintain that asthma patients should have the following laboratory tests done at least once a year:

- lung-function tests used in patients with chronic respiratory disorders to assess the respiratory function and to determine the extent of dysfunction

- spirometry tests that include measurements of lung volumes and ventilatory function, as well as the mechanics of breathing, diffusion and gas exchange

- peak-flow rate reflecting the maximum expiratory flow

- arterial blood gas studies that are used to measure the acid-base $(\mathrm{pH})$ of blood of arterial oxygen and carbon dioxide tensions.

Many respondents $(57.4 \% ; n=31)$ did not go for laboratory tests, whilst $35.2 \%(n=19)$ went once a year. Two $(3.7 \%)$ respondents indicated that they went every six months for laboratory tests, whilst another two (3.7\%) indicated that they had laboratory tests done every three months. The lungfunction tests are usually done in cases of severe asthma. McCance and Huether (2006:1200) acknowledge that these laboratory tests are expensive, yet they provide valuable information about the progression or resolution of the illness.

\section{The asthma status of the respondents}

Of the respondents participating in the study, 50\% $(n=27)$ indicated that they did not experience asthma attacks,

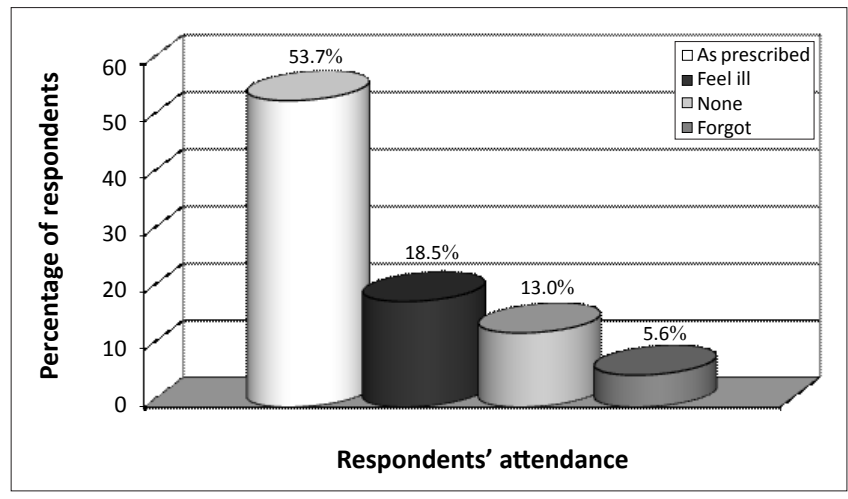

Source: Original data

FIGURE 2: The percentage of respondents who took their asthma medications as prescribed, when they felt ill, not at all or when they did not forget to do so. 
whereas $37.0 \%(n=20)$ had attacks one to five times a year, $7.4 \%(n=4)$ six to ten times a year, and $5.6 \%(n=3)$ had 11 or more asthma attacks per year. The number of asthma attacks experienced by the respondents corresponded with the number of visits made to their private doctors. A few more than a half $(53.7 \% ; n=29)$ did not visit a private doctor, $38.9 \%$ $(n=21)$ visited their doctors one to five times a year, 3.7\% $(n=2)$ visited their doctors six to ten times a year, and another $3.7 \%(n=2)$ visited their doctors 11 or more times a year.

\section{Knowledge about the disease}

Patients cooperate better with health-care providers if they have sufficient knowledge of a disease and its treatment. According to Huber (2006:370), one of the strategies of disease management is to '... help identify knowledge deficits and counselling needs'. Questions were asked about the respondents' knowledge of asthma. The majority of the respondents $(83.3 \% ; n=45)$ knew that asthma is a chronic disease of the airways, $9.3 \%(n=5)$ said that asthma is a disease of the lungs, 3.7\% $(n=2)$ defined it as a chest infection, and $3.7 \%(n=2)$ stated that the disease affects smokers. Out of 50 respondents, $96.0 \%(n=48)$ knew that there is no cure for asthma, yet $4.0 \%(n=2)$ thought that such a cure existed.

The majority $(92.6 \% ; n=50)$ of the respondents understood that one could live a normal life when taking medications as prescribed, whilst $53.7 \%(n=29)$ said that one could live a healthy life if one stopped smoking; $18.5 \%(n=10)$ believed that one could live a normal life by taking the prescribed medications when ill (respondents could select more than one answer in response to this question).

The respondents indicated that their asthma attacks were triggered by allergies $(83.3 \% ; n=45)$, dust $(63.0 \% ; n=34)$ and smoking $(44.4 \% ; n=24)$. In addition to those who indicated that allergies caused asthma, the asthma-causing effects of the hairs of cats or dogs were specified by $42.6 \%(n=23)$ respondents.

Respondents thought that the narrowing of the airways during asthma attacks was caused by the swelling of the inner lining of the breathing tubes $81.5 \%(n=44)$; by increased sticky mucous $40.7 \%(n=22)$, or by muscle spasms $(37.0 \%$; $n=20$ ). The respondents did not understand what happened during asthma attacks. Taylor, Auble, Calhoum, Mesesso and Mesesso (1999:1645) also found that asthma patients suffered from a lack of knowledge about their condition and about its effective management.

\section{Compliance with medication}

Of the respondents, $68.5 \%(n=37)$ used preventer pumps, $50.0 \%(n=27)$ used reliever pumps, $20.4 \%(n=11)$ took tablets orally, $5.6 \%(n=3)$ took no medication, and $3.7 \%$ $(n=2)$ used aminophyllin (fourteen respondents [7.5\%] did not answer this question, but each respondent could select more than one option). Approximately half the respondents $53.7 \%(n=29)$ took their treatment as prescribed, $18.5 \%$ $(n=10)$ took medication when they felt ill, $13.0 \%(n=7) \mathrm{did}$ not take treatment at all, and $5.6 \%(n=3)$ forgot to take their medication.

It is important for asthma patients to take their medications regularly even if they do not feel ill, as it places patients in control of their condition rather than allowing the disease to control them. Most asthma sufferers take their treatment by the use of inhalers, but there is medication in the form of tablets. Smeltzer and Bare (2004:589) state that ' $\ldots$ the route of choice for administration of these medications is the MDI (metered dose inhalers) because it allows for topical administration'. The direct administration of inhalers to the lungs permits the use of lower doses of medicines than would be required in the case of oral medicines absorbed through the gastro-intestinal tract and then transported to the lungs.

Out of the $36(68.5 \%)$ respondents who reportedly used preventer pumps, $41.7 \%(n=15)$ knew how to use these correctly, and $8.1 \%(n=3)$ admitted that they lacked this knowledge. Teaching patients how to use their medications correctly is a critical component of providing care for the patient with asthma. Smeltzer and Bare (2004:594) are of the opinion that '... multiple inhalers; different types of inhalers; anti-allergy therapy; anti-reflux medication; and avoidance measures are all integral to the long-term control of asthma'.

\section{Stress levels}

Of the respondents, $46.3 \%(n=25)$ indicated that they experienced moderate stress levels, whereas $44.4 \%(n=24)$

TABLE 1: Respondents' perceptions regarding the asthma disease risk-management (DRM) programme of the medical aid scheme.

\begin{tabular}{|c|c|c|c|c|c|c|c|}
\hline \multirow[t]{2}{*}{ The asthma DRM programme of the medical aid scheme } & \multicolumn{2}{|c|}{ Disagree } & \multicolumn{2}{|c|}{ Unsure } & \multicolumn{2}{|c|}{ Agree } & \multirow[t]{2}{*}{ Total } \\
\hline & $n$ & $\%$ & $n$ & $\%$ & $n$ & $\%$ & \\
\hline Provides enough information on asthma as a disease & 7 & 21.9 & 16 & 50 & 9 & 28.1 & 32 \\
\hline Provides enough information on asthma medication & 10 & 27.7 & 15 & 41.7 & 11 & 30.6 & 36 \\
\hline Provides an understanding of the DRM services & 12 & 34.3 & 12 & 34.3 & 11 & 31.4 & 35 \\
\hline Provides sufficient information about medical check-ups & 13 & 38.2 & 11 & 32.4 & 10 & 29.4 & 34 \\
\hline Provides an understanding of asthma triggers and their avoidance & 15 & 44.1 & 10 & 29.4 & 9 & 26.5 & 34 \\
\hline Improves understanding of using preventer pumps effectively & 14 & 41.2 & 10 & 29.4 & 10 & 29.4 & 34 \\
\hline Helps understanding of using reliever pumps effectively & 14 & 42.4 & 10 & 30.3 & 9 & 27.3 & 33 \\
\hline Helps patients to understand the importance of regular exercises & 13 & 40.6 & 10 & 31.3 & 9 & 28.1 & 32 \\
\hline Encourages patients to maintain a normal body weight & 15 & 44.1 & 10 & 29.4 & 9 & 26.5 & 34 \\
\hline Enables patients to understand a healthy eating plan & 15 & 44.1 & 10 & 29.4 & 9 & 26.5 & 34 \\
\hline Helps patients to understand how asthma medications work & 15 & 44.1 & 10 & 29.4 & 9 & 26.5 & 34 \\
\hline Helps to manage asthma and prevent hospitalisations or attacks & 15 & 42.9 & 10 & 28.6 & 10 & 28.6 & 35 \\
\hline
\end{tabular}


reported mild stress levels, and 9.3\% $(n=5)$ experienced severe stress levels. Smeltzer and Bare (2004:54) state that stress management and the reduction of general stress levels are important aspects of health promotion for patients living with asthma. Apparently at least $55.3 \%(n=30)$ of the respondents involved in this study could have benefitted from stress management programmes. Klinnert (2003:574) states that severe negative life events increase the risk of children having asthma attacks over subsequent weeks following these stressful events. Consequently, children suffering from asthma should be assisted to manage their stress levels effectively and their caregivers and/or parents should know how to help them.

\section{Respondents' opinions about the asthma disease risk-management programme}

The respondents' perceptions about the asthma DRM programme are portrayed in Table 1 . The most important shortcomings of the asthma DRM programme, according to the respondents' perceptions, were that it failed to enable them to:

- identify asthma triggers and to avoid them $(44.1 \% ; n=15)$

- understand how asthma medications work $(44.1 \% ; n=15)$

- maintain normal body weight $(44.1 \% ; n=15)$

- understand a healthy eating plan $(44.1 \% ; n=15)$

- manage asthma and prevent attacks or hospitalisations $(42.9 \% ; n=10)$

- use reliever pumps effectively $(42.4 \% ; n=14)$

- use preventer pumps effectively $(41.2 \% ; n=14)$

- understand the importance of regular exercises $(40.6 \%$; $n=13)$

- comprehend the importance of regular medical check-ups $(38.2 \% ; n=13)$.

\section{Respondents' perceptions about the case managers} of the asthma disease risk-management programme

As many as 25 (46.3\%) of the respondents were neither aware that an asthma DRM programme existed, nor that there were case managers for such a programme.

Of the respondents $16.7 \%(n=5)$ regarded the case manager as being knowledgeable about asthma, $14.3 \%(n=4)$ agreed that the case manager phoned patients at regular intervals to monitor their progress, and $14.3 \%(n=4)$ agreed that the case manager sent patients their treatment plans - explaining their prescribed minimum benefits - on time.

\section{Respondents' feelings about the asthma disease risk-management programme}

Out of 54 respondents, only $46.3 \%(n=25)$ answered the openended question requesting them to describe any problems that they had encountered with the DRM programme. These respondents indicated that they were unaware of an asthma DRM programme. Only one respondent indicated that he or she had obtained some information about the asthma DRM programme from reading a pamphlet.

When asked (in an open-ended question) which benefits the asthma DRM programme had for asthma patients, only 17 respondents answered this question: $76.5 \%(n=13)$ were unsure of these benefits, $17.6 \%(n=3)$ said that there were no benefits, and $5.9 \%(n=1)$ said that the programme prevented asthma attacks.

In response to an open-ended question that asked what could be done to improve compliance amongst asthma patients, 22 respondents $(40.7 \%)$ answered as follows:

- Eight respondents (36.4\%) suggested that patients should be contacted and be made aware of the DRM programme.

- Three respondents (13.6\%) suggested that information and knowledge should be given to patients by means of an electronic mailing system.

- Two respondents $(9.1 \%)$ suggested that the relationship between the case manager and the patient should be improved and that patients should be motivated to manage their illness.

- One respondent (4.5\%) suggested that patients should be educated about chronic medication.

- Improved communication between case managers and patients could enhance asthma patients' compliance levels according to one $(4.5 \%)$ respondent.

- The DRM programme should address the cost of chronic medication $(4.5 \% ; n=1)$.

- One (4.5\%) respondent proposed that the DRM programme needed to be better promoted so that all patients would know how to enrol for the programme and which benefits the programme could have for patients suffering from asthma.

\section{Limitations of the study}

The study focused only on the members (and their dependants) of one medial aid scheme. Asthma sufferers who belong to different medical aid schemes may have different perceptions of an asthma DRM programme.

Only self-completion questionnaires were used in this study. More in-depth data could be obtained by conducting individual interviews.

Despite sending out reminders to complete the questionnaires, the response rate was low at $27.0 \%$ (only 54 of 200 completed questionnaires were returned). The small number of respondents might have limited the reliability and the validity of the findings of the study. The large number of 'unsure' responses might have compromised the validity of the research results.

\section{Recommendations}

There is a need to educate patients about regular exercise, healthy eating habits, the importance of not smoking, regular visits to a treating doctor, taking medication as prescribed, and regular laboratory tests. Members of the medical aid scheme should be empowered by the necessary knowledge to successfully manage their condition and, by so doing, prevent asthma attacks and admissions to emergency departments and/or hospitals. When the 
condition is well managed, the patients' quality of life could improve and the costs of the medical aid scheme could be contained.

The importance of enabling more asthma patients to comply with the DRM programme of a particular medical aid scheme cannot be overemphasised in the struggle to prevent complications, reduce hospital admissions, and improve asthma patients' quality of life. Not only will the asthma patients themselves benefit from the DRM programme, but also their dependants and/or family members.

\section{Conclusion}

Many asthma patients failed to comply with the DRM programme owing to a lack of knowledge about the programme. The DRM programme had reportedly not been promoted effectively. This lack of knowledge about the DRM programme might have compromised some asthma patients' quality of life, and the importance of effective marketing of this DRM programme cannot be overemphasised.

\section{Acknowledgements}

We wish to thank the participating medical aid scheme for granting permission for the study to be conducted and for publishing this article. Every respondent who completed a questionnaire is thanked for his or her contribution, without which this research project could not be completed.

\section{Competing interests}

No funds were received for this project and the participating medical aid fund imposed no limits on the study, except for the request to remain anonymous.

\section{Authors' contributions}

N.O. conducted the study for her Masters dissertation, J.H.R. was the supervisor, and V.J.E. was the joint supervisor. N.O. obtained permission for the study and collected the data. V.J.E. and J.H.R. guided the research process from its conception until its conclusion. V.J.E. and J.H.R. assumed the major responsibility for getting the article written, based on the Masters dissertation, and for continuing with the process until publication, with inputs from the other authors when requested.

\section{References}

Ayres, J., 2006, Understanding asthma, Family Doctor Books, Dorset.

Berkow, R., Beers, M.H., Bogin, R.M. \& Fletcher, A.J., 1998, The Merck Manual of Medical Information, Home edn, Merck Research Laboratories, Whitehouse Station, New Jersey.

Burns, N. \& Grove, S.K., 2005, The practice of nursing research: Conduct, critique and utilization, 5th edn., Saunders, Philadelphia.

Burns, N. \& Grove, S.K., 2007, Understanding nursing research. Building an evidencebased practice, 4th edn., Saunders Elsevier, St Louis.

Brooker, C. (ed.), 2006, Mosby nurse's pocket dictionary, 33rd edn., Elsevier Mosby, London.

De Villiers, A., Van der Merwe, C.A. \& Van Wyk Kotze, T.J., 2004, 'Classification of a member in terms of healthcare risk', South African Journal of Business Management 35(4):21-25.

Elliott, R.A., 2006, 'Poor adherence to anti-inflammatory medication in asthma', Practical Disease Management 14(4):223-233.

Foltz-Gray, D., 1997, 'Map or maze? Confused about disease management? Here's how to make it work', Contemporary Long Term Care 20(12):223-233.

Goldstein, P.C., 2006, 'Impact of disease management programs on hospital and community nursing practice', Nursing Economics 24(6):308-314. PMid: 17266007

Huber, D.L., 2006, Leadership and nursing care management, 3rd edn., Saunders Elsevier, Philadelphia.

Jeena, P., Morris, A. \& Luyt, D., 2004, What is asthma?, Department of Health (Provincial Government of the Western Cape Province), viewed on 05 December 2007, from www.allergysa.org/whatis.htm -17k

Klinnert, M.D., 2003, 'Evaluating the effects of stress on asthma: a paradoxical challenge', European Respiratory Journal 22:574-575. doi:10.1183/09031936.03. 00067903, PMid: 14582904

Kolbe, J., 2002, 'The influence of socioeconomic and psychological factors on patient adherence to self-management strategies. Lessons learned in asthma', Disease adherence to self-management strategies. Lessons learned in asthma', Disease
Manage Health Outcomes 10(9):551-670. doi:10.2165/00115677-20021009000004

Mackinnon, L.T., 2000, 'Chronic exercise training effects on immune function', Medicine \& Science in Sports \& Exercise 32(7 Suppl.):S369-372. doi:10.1097/00005768200007001-00001

Mash, R., Ainslie, G., Irusen, E., Mayers, P. \& Bheekie, A., 2007, 'The dissemination and implementation of national asthma guidelines in South Africa: the use of outcomes mapping', SA Family Practice Journal 49(5):5-8.

McCance, K.L. \& Huether, S.E., 2006, Pathophysiology. The biological basis for disease in adults and children, 5th edn., Elsevier Mosby, St Louis.

Medical News Today, 2005, Is Obesity a Risk Factor For Asthma?, viewed 10 May 2005 from http://www.medicalnewstoday.com/articles/24118.php

Merriam Webster Dictionary, 2011, viewed 26 July 2011, from http://www.merriam webster.com/dictionary/compliance

MIMS - See Monthly Index of Medical Specialties.

Johannesburg, John Commercial Media Investments, 2007, MIMS, July: 47(7).

Murphy, K.R., 2005, 'Asthma: versatile treatment for a variable disease', Journal of Asthma 42:149-157. doi:10.1081/JAS-54649, PMid: 15962869

Polit, D.F. \& Beck, C.T., 2004, Nursing research: Principles and methods, 7th edn., J.B. Lippincott, Philadelphia.

Promtussananon, S., 2003, 'Perceptions on physiopathology and preferred treatment of epilepsy and asthma in the Limpopo province South Africa', Health SA Gesondheid 8(1):67-77.

Smeltzer, S.C. \& Bare, B.G., 2004, Brunner and Suddarth's textbook of medical-surgical nursing, 10th edn., Lippincott, Williams \& Wilkins, Philadelphia.

Smeltzer, S.C., Bare, B.G., Hinkle, J.L. \& Cheever, K.H., 2008, Brunner and Suddarth's textbook of medical-surgical nursing, 11th edn., Lippincott, Williams \& Wilkins, Philadelphia.

South Africa, 1998, Medical Schemes Act 131. Government Printer, Pretoria.

Taylor, D.M., Auble, T.E., Calhoum, W.J., Mesesso, F.C.C.P. \& Mesesso, V.N.J.R., 1999,

'Current outpatient management of asthma shows poor compliance with international consensus guidelines', American College of Chest Physicians 116:1638-1645.

The New Collins Compact Dictionary of the English Language, 2000, Collins, London. WHO - See World Health Organization.

World Health Organization, 2007, Chronic respiratory diseases, viewed 05 December 2007, from www.who.int/respiratory/asthma/en 